\title{
РЕАЛІЗАЦІЯ КЕРУВАННЯ ЗА ПРОГНОЗОМ НА ОСНОВІ КУБІЧНОГО СПЛАЙНУ В ЗАМКНУТИХ САР: КОНЦЕПЦІЯ ПОБУДОВИ І ПОПЕРЕДНІЙ АНАЛІЗ РОБОТИ
}

\section{Степанов М. T.}

Одеська національна академія харчових технологій, м. Одеса, Україна

ORCID: https://orcid.org/0000-0003-1297-5537

E-mail: stepanov197818@gmail.com

Copyright (C) 2020 by author and the journal "Automation of technological and business - processes". This work is licensed under the Creative Commons Attribution International License (CC BY). http://creativecommons.org/licanses/by/4.0

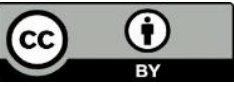

ONAFT

Open Access

\section{DOI: https://doi.org/10.15673/atbp.v12i4.1929}

\begin{abstract}
Анотація. У статті розглядається система автоматичного регулювання, щзо реалізує принцип керування за прогнозом в замкнутому контурі. Об'єкти технологічного типу досить часто мають велику інерційність в каналах регулювання яка пов'язаної не тільки з чистим запізненням, але, більшою мірою з акумуляцією речовини і енергї, так званим ємнісним запізненням. Повна або часткова компенсація ичієї інериійності може в значній мірі поліпшити якість регулювання для таких об'єктів. Тому в замкнутий контур системи регулювання пропону-ється ввести прогнозування на основі кубічного сплайну. Проведений аналіз показує, щзо окремі ділянки траєк-торії руху регульованої змінної можуть бути представлені безперервними, багаторазово диференційованими функціями (наприклад, кубічним сплайном). Для моделі кубічного сплайну знайдені співвідношення, щзо дозволя-ють оцінювати його параметри і вести розрахунок прогнозного значення змінної в реальному часі. Проведено структурний та оптимальний параметричний синтез альтернативних варіантів систем автоматичного ре-гулювання з типовим ПІД-регулятором, щцо реалізують принциип керування за прогнозом і принции керування за станом. Порівняльний аналіз оптимальних систем, проведений в часовій $i$ частотних областях, показав значну перевагу системи регулювання, щзо реалізує принции керування за прогнозом на основі кубічного сплайну. У по-рівнянні з системою, щзо реалізує принцип керування за станом, система регулювання з прогнозуванням по кубі-чному сплайну забезпечує зниження інтегрального і прямих показників якості перехідних процесів до 40\%. Пе-ревірка на грубість систем автоматичного регулювання показала, що система автоматичного регулювання з прогнозуванням регульованої змінної за кубічним сплайном має більший запас стійкості, ніж система регулю-вання шуо реалізує принцип керування за станом.
\end{abstract}

Abstract. The article discusses an automatic control system that implements the principle of predictive control in a closed loop. Objects of a technological type quite often have a large inertia in the control channels associated not only with a pure delay, but, to a greater extent, with the accumulation of matter and energy, the so-called capacitive delay. Full or partial compensation of this inertia can significantly improve the quality of regulation for such objects. Therefore, it is proposed to introduce prediction based on a cubic spline into the closed loop of the control system. The performed analysis shows that individual sections of the trajectory of the controlled variable can be represented by continuous, multiply differentiable functions (for example, a cubic spline). For the model of cubic splines, relations are found that allow estimating their parameters and calculating the predicted value of the variable in real time. Structural and optimal parametric synthesis of alternative variants of automatic control systems with a typical PID controller, which implement the principle of control by forecast and the principle of control by state, has been carried out. A comparative analysis of optimal systems, carried out in the time and frequency domains, showed a significant advantage of the control system that implements the principle of predictive control based on a cubic spline. In comparison with a system that implements the principle of state control, a control system with predictive cubic spline provides a decrease in the integral and direct quality indicators of transient processes by up to $40 \%$. Checking for the roughness of automatic control systems showed that an automatic control system with predicting an adjustable variable along a cubic spline has a greater margin of stability than a control system that implements the principle of state control.

Ключові слова: прогнозування, кубічний сплайн, помилка прогнозування, система автоматичного регулювання, запас стійкості.

Keywords: prediction, cubic spline, prediction error, automatic control system, robust control. 
http://www.atbp.onaft.edu.ua/

\section{Ветуп}

Основними характеристиками замкнутих САР є якість регулювання і стійкість. Якість регулювання визначається динамічної та статичної точністю САР. Максимально досяжна динамічна точність САР багато в чому обмежується запізненням і інерційністю каналів об'єкта керування. Об'єкти технологічного типу досить часто мають велику інерційністю в каналах регулювання, пов'язаної не тільки з чистим запізненням, але, більшою мірою з акумуляцією речовини і енергії, так званим ємнісним запізненням. Повна або часткова компенсація цієї інерційності може в значній мірі поліпшити якість регулювання для таких об'єктів. Тому в замкнутий контур системи регулювання пропонується ввести прогнозування на основі кубічного сплайну і перейти від загальноприйнятого принципу регулювання по поточному значенню вихідної величини у (t) до принципу регулювання за прогнозом $\mathrm{y}(\mathrm{t}+\tau \Pi p)$. Це означає що обчислення керуючого впливу (положення регулюючого органу) $U$ (t) проводиться не за поточним значенням регульованої величини у $(\mathrm{t})$, а по прогнозованому значенню $\mathrm{y}(\mathrm{t}+\tau$ пр) у майбутньому.

\section{Аналіз літературних даних і постановка проблеми}

Аналіз сучасних підходів [2,3] підтверджує актуальність використання принципу управління за прогнозом в сучасних САР. Прогнозування в САР може здійснюватися за різними законами. В [2, 3] розглянуті варіанти САР, що реалізують принцип замкнутого керування за лінійним прогнозом у (t). Ідеальне (фізично не реалізується) прогнозування має передатну функцію

$$
\mathrm{W}(\mathrm{p})=\mathrm{e}^{+\mathrm{p} \tau \mathrm{rp}}
$$

Якщо розкласти експонентну функцію (1) в ряд Тейлора

$$
\mathrm{e}^{+\mathrm{p} \tau_{\mathrm{tp}}}=1+\mathrm{p} \tau_{\text {tip }}+\frac{\left(\mathrm{p} \tau_{\text {tip }}\right)^{2}}{2 !}+\frac{\left(\mathrm{p} \tau_{\text {tp }}\right)^{3}}{3 !}+\ldots
$$

і обмежитися в (2) першими двома складовими, то отримаємо передавальну функцію найпростішого - лінійного прогнозу:

$$
\mathrm{W}_{\text {пр }}(\mathrm{p})=1+\mathrm{p} \tau_{\text {пр }}
$$

Передаточна функція (3) представляє ідеальну форсуючу ланку. Її включення в контур зворотного зв'язку для прогнозування у (t) дозволило підвищити динамічну точність САР. Одночасно проведений в [1] аналіз показує, що окремі ділянки траєкторії руху регульованої змінної можуть бути представлені безперервними, багаторазово диференційованими функціями (сплайнами). В якості найбільш ефективного розглядається кубічний сплайн. Для моделей кубічного сплайна знайдені співвідношення, що дозволяють оцінювати їх параметри в реальному часі і вести розрахунок прогнозного значення змінної. Результати досліджень показали, що використання кубічного сплайна дозволяє досить точно прогнозувати значення гармонійних сигналів на інтервалах менших полупериода, а випадкових гауссовских процесів на інтервалах менших одного, двох інтервалів кореляції, при цьому великі інтервали прогнозування відповідають вузькосмуговим, близьким до квазігармонійного випадковим процесам. Отримані результати підтверджують можливість включити обраний сплайн для прогнозування відфільтрованих від шумів регульованих змінних без великих похибок на час порівнянне з часом запізнювання в каналі керування. Тому в якості альтернативи лінійному прогнозу пропонується вести прогноз на основі кубічного сплайну (полінома третього ступеня). Але це вимагає додаткових досліджень розроблених алгоритмів в ланцюгах САР.

\section{Мета і завдання дослідження}

Метою дослідження є синтез і попередній аналіз підвищення динамічної точності та запасу стійкості САР, що реалізує принцип управління за прогнозом на основі кубічного сплайна для об'єктів технологічного типу, коли регульовану змінну можна розглядати як багаторазово диференційовану функцію часу в порівнянні з САР, що реалізує замкнутий принцип управління станом. Для цього, в контур зворотного зв'язку замкнутої САР вводиться математична модель прогнозування регульованої змінної на основі кубічного сплайна. Для досягнення поставленої мети необхідно провести структурний і оптимальний параметричний синтез САР, що реалізує принцип управління станом і САР, що реалізує принцип управління за прогнозом. Після цього провести порівняльний аналіз цих систем.

\section{Методи і матеріали досліджень}

Для проведення досліджень в якості основного методу будемо використовувати метод імітаційного моделювання в середовищі Simulink системи Matlab. Для цього на першому етапі розробимо структурну схему САР, визначимо регулятор, віртуальний тестовий ОК (ВТОК), критерій оцінки якості роботи САР і проведемо для моделі кубічного сплайна розрахунок співвідношень, що дозволяють оцінювати його параметри в реальному часі і вести розрахунок прогнозного значення регульованої змінної. Структурна схема САР яка реалізує принцип керування за прогнозом представлена на рисунку 1.

В якості регулятора будемо використовувати ПІД-регулятор з реальним диференціатором. Для проведення оптимального параметричного синтезу САР і оцінки якості їі роботи в перехідних режимах скористаємося інтегральним квадратичним показником якості: 


$$
I=\int_{t_{1}}^{t_{1}+\text { Тммо }}\left(y^{32}(t)-y(t)\right)^{2} d t
$$

де $\mathrm{T}_{\text {мод }}$ - час моделювання, $\mathrm{t}_{1}$ - час початку відліку.

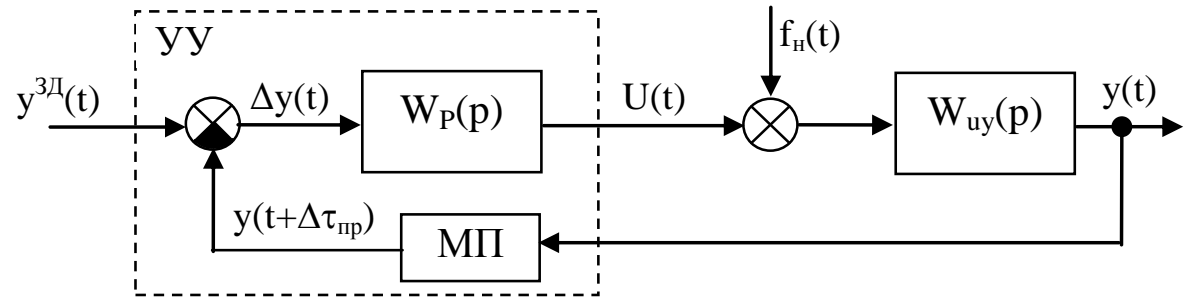

Рис. 1 - Структурна схема САР з модулем прогнозування в її контурі зворотного зв'язку

Модель об'єкта керування розглянемо зі статичними властивостями за каналом керування. Передаточна функція віртуального тестового ОУ (ВТОУ) має наступний вигляд.

$$
\mathrm{W}_{\mathrm{uy}}^{o}(\mathrm{p})=\frac{\mathrm{ko}}{(\mathrm{T} 1 \mathrm{p}+1)^{6}(\mathrm{~T} 2 \mathrm{p}+1)}
$$

де Т1 - постійна часу що характеризує ємнісне запізнення, Т2 - постійна часу, kо - коефіцієнт передачі ОК. При цьому постійна часу T1 << Т2. Для проведення досліджень були прийняті наступні базові значення параметрів ВТОУ: $\mathrm{T} 1=0.5, \mathrm{~T} 2=7, \mathrm{ko}=1.2$.

На рисунку 2 представлена нормована перехідна характеристика ВТОУ по каналу керування 3 ілюстрацією процедури параметричної ідентифікації моделі першого порядку за методикою Мініної.

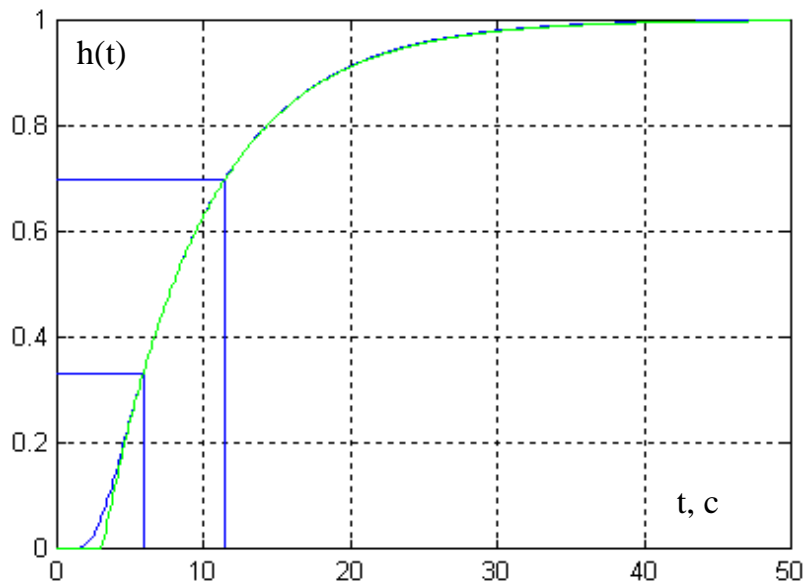

Рис. 2 - Ілюстрація процедури параметричної ідентифікації моделі ОК (методика Мініной) за каналом керування

Передаточна функція моделі першого порядку по каналу керування.

$$
\mathrm{W}_{\mathrm{uy}}(\mathrm{p})=\frac{1.2 e^{-3.1 p}}{7 p+1}
$$

Модуль прогнозування по кубічному сплайну будемо реалізовувати на основі наступного виразу:

$$
\begin{gathered}
\mathrm{y}\left(\mathrm{t}+\Delta_{\text {пр }}\right)=\bar{y}(\mathrm{t})+\mathrm{d}(\mathrm{t})\left(\mathrm{t}+\Delta_{\text {пр }}\right)^{3}+\mathrm{c}(\mathrm{t})\left(\mathrm{t}+\Delta_{\text {пр }}\right)^{2}+\mathrm{b}(\mathrm{t})\left(\mathrm{t}+\Delta_{\text {пр }}\right)+\mathrm{a}(\mathrm{t}), \\
\Delta \tau_{\text {пр }} \in\left[0, \tau_{\text {пр }}\right] .
\end{gathered}
$$

Тоді, якщо вдасться знайти значення трьох похідних цих оцінок в момент часу $t=t 0$, то оцінки значень коефіцієнтів в (7) визначаються з простих і зручних для розрахунку в реальному часі співвідношень:

$$
\begin{gathered}
\mathrm{d}\left(\mathrm{t}_{0}\right)=\dddot{\mathrm{y}}\left(\mathrm{t}_{0}\right) / 6, \\
\mathrm{c}\left(\mathrm{t}_{0}\right)=\left(\ddot{\mathrm{y}}\left(\mathrm{t}_{0}\right)-\dddot{\mathrm{y}}\left(\mathrm{t}_{0}\right) \mathrm{t}_{0}\right) / 2,
\end{gathered}
$$




$$
\begin{gathered}
\mathrm{b}\left(\mathrm{t}_{0}\right)=\dot{\mathrm{y}}\left(\mathrm{t}_{0}\right)-\ddot{\mathrm{y}}\left(\mathrm{t}_{0}\right) \mathrm{t}_{0}+\dddot{\mathrm{y}}\left(\mathrm{t}_{0}\right) \mathrm{t}_{0}^{2} / 2, \\
\mathrm{a}\left(\mathrm{t}_{0}\right)+\overline{\mathrm{y}}\left(\mathrm{t}_{0}\right)=\mathrm{y}\left(\mathrm{t}_{0}\right)-\dot{\mathrm{y}}\left(\mathrm{t}_{0}\right) \mathrm{t}_{0}+\ddot{\mathrm{y}}\left(\mathrm{t}_{0}\right) \mathrm{t}_{0}^{2} / 2-\dddot{\mathrm{y}}\left(\mathrm{t}_{0}\right) \mathrm{t}_{0}^{3} / 6,
\end{gathered}
$$

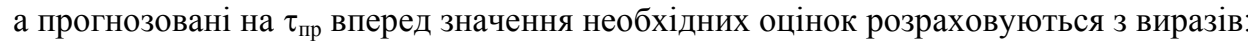

$$
\mathrm{y}\left(\mathrm{t}_{0}+\tau_{\text {tip }}\right)=\mathrm{d}\left(\mathrm{t}_{0}\right)\left(\mathrm{t}_{0}+\tau_{\text {trp }}\right)^{3}+\mathrm{c}\left(\mathrm{t}_{0}\right)\left(\mathrm{t}_{0}+\tau_{\text {tip }}\right)^{2}+\mathrm{b}\left(\mathrm{t}_{0}\right)\left(\mathrm{t}_{0}+\tau_{\text {tip }}\right)+\mathrm{a}\left(\mathrm{t}_{0}\right)+\overline{\mathrm{y}}\left(\mathrm{t}_{0}\right),
$$

Необхідною умовою роботи алгоритму, $є$ щоб $\mathrm{y}(\mathrm{t})$ була триразово диференційованою. Ця умова цілком здійсненна, так як змінні на виході ОК, відфільтровані від шумів, як правило, є багато разів диференційованими.

У розглянутому сплайні розрахунок коефіцієнтів ведеться в припущенні, що в момент $\mathrm{t}_{0}$ відомі значення самої змінної і всіх необхідних похідних. У разі цифрової реалізації алгоритму керування, а саме вона передбачається як основна, похідні обчислюються за значеннями решітчастої функції $\mathrm{f}_{\mathrm{k}}\left(\mathrm{nT}_{\mathrm{KB}}\right), n=\overline{0, \infty}, 3$ кроком квантування $\mathrm{T}_{\text {кв}}$.

Для проведення порівняльного аналізу роботи САР введемо такі позначення: САРП_Л - САР реалізує принцип управління за прогнозом на основі лінійного прогнозу (3); САРП_К - САР реалізує принцип управління за прогнозом на основі кубічного сплайну (9).

На першому етапі досліджень проведемо оптимальний параметричний синтез (ОПС) САР за критерієм (4) при фіксованих параметрах моделі ОУ без модулів прогнозування. А потім в замкнутий контур отриманої САР 3 оптимальними параметрами регулятора введемо модулі прогнозування 3 лінійним прогнозом і прогнозом по кубічному сплайну. Схеми моделювання САР і результати ОПС представлені на рисунку 3.

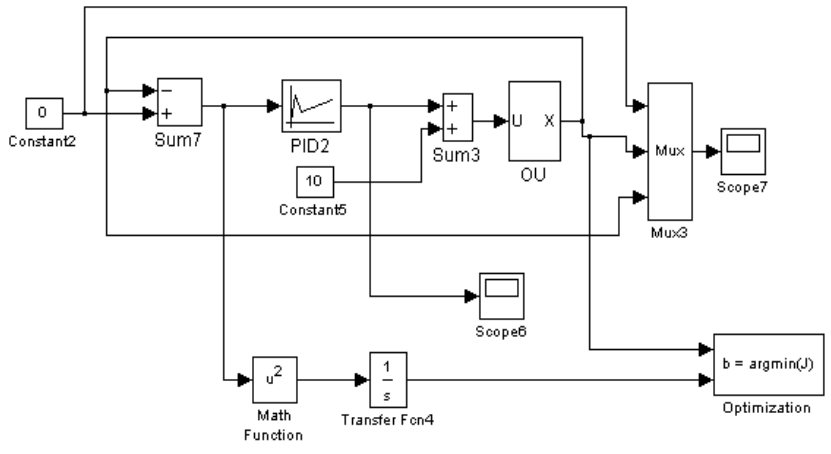

a)

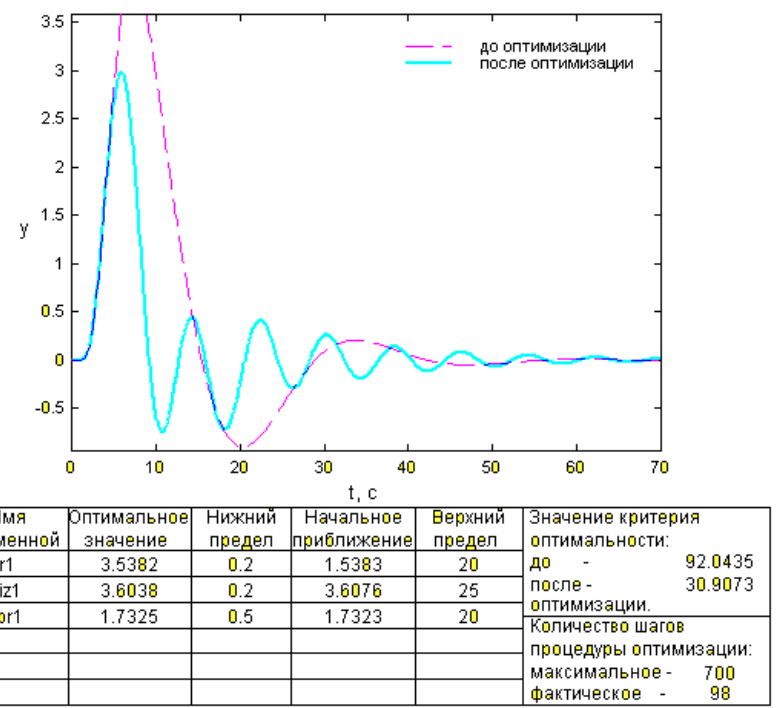

в)

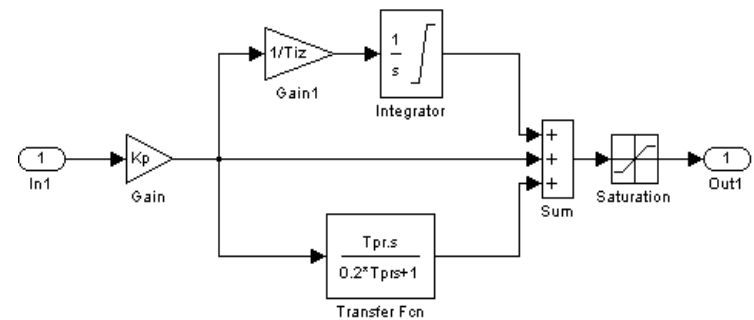

б)

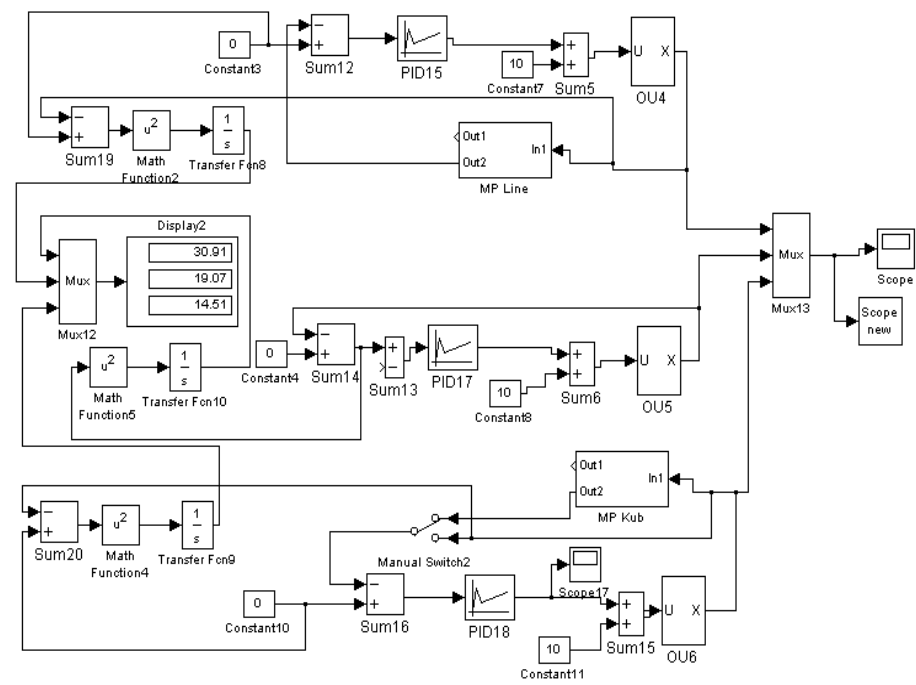

г)

Рис. 3 - Схема моделювання САР (а) з розкритою підсистемою ПІД регулятора (б), результати її оптимального параметричного синтезу (в) при фіксованих значеннях параметром моделі ВТОУ і схема моделювання САР 3 доданими модулями прогнозування (г) 


\section{Результати досліджень та їх обговорення}

Введення в замкнутий контур САР оптимальної за критерієм (4) модуля 3 лінійним законом прогнозування підвищує динамічну точність САР, але не забезпечує значного підвищення запасу їі стійкості в порівнянні 3 прогнозуванням по кубічному сплайну. На рисунку 4 представлені перехідні характеристики САР для різних значень

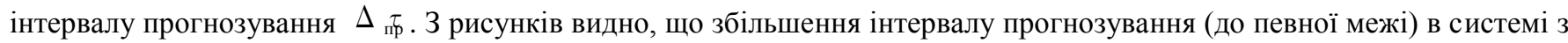
кубічним сплайном призводить до підвищення динамічної точності (зменшується $\Delta y^{\max }$ ) і підвищення запасу стійкості в порівнянні з базовою САР і САР з лінійним законом прогнозування.

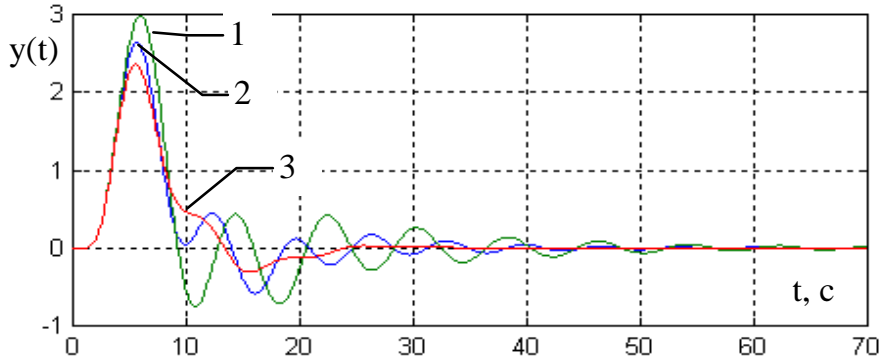

\begin{tabular}{|c|c|c|}
\hline Вариант CAP & $\Delta \mathrm{y}^{\max }$ & I \\
\hline 1. $\mathrm{CAP}$ & 2.98 & 30.9 \\
\hline 2. CAPח_Л $\left(\Delta \tau_{m p}=0.5\right)$ & 2.64 & 22.1 \\
\hline 3. CAPח_K $\left(\Delta \tau_{\mathrm{mp}}=0.7\right)$ & 2.36 & 18.8 \\
\hline
\end{tabular}

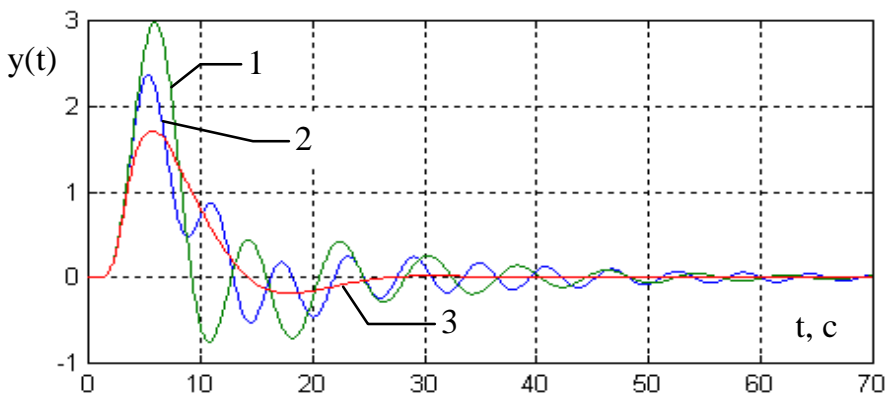

\begin{tabular}{|l|c|c|}
\hline Bapиант CAP & $\Delta \mathrm{y}^{\max }$ & $\mathrm{I}$ \\
\hline 1. CAP & 2.98 & 30.9 \\
\hline 2. CAPח_Л $\left(\Delta \tau_{m \mathrm{p}}=0.9\right)$ & 2.37 & 19.1 \\
\hline 3. CAPח_K $\left(\Delta \tau_{m \mathrm{p}}=1.4\right)$ & 1.71 & 14.5 \\
\hline
\end{tabular}

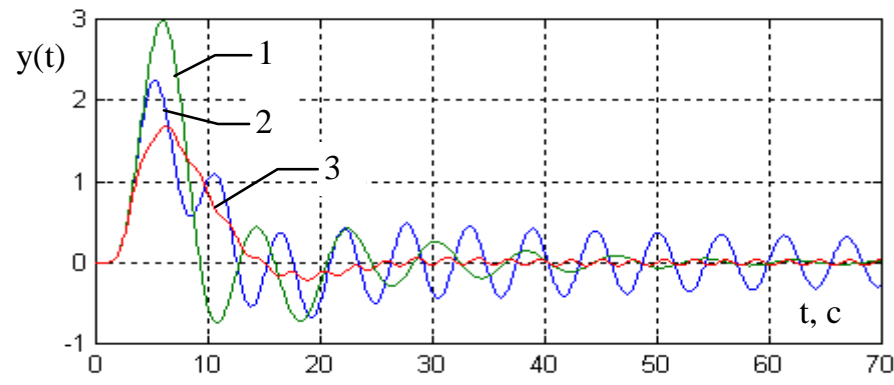

\begin{tabular}{|c|c|c|}
\hline Вариант CAP & $\Delta \mathrm{y}^{\max }$ & $\mathrm{I}$ \\
\hline 1. CAP & 2.98 & 30.9 \\
\hline 2. CAPח_ $\Pi\left(\Delta \tau_{m p}=1.1\right)$ & 2.25 & 21.9 \\
\hline 3. CAPח_K $\left(\Delta \tau_{\text {mp }}=1.6\right)$ & 1.68 & 13.9 \\
\hline
\end{tabular}

Рис. 4 - Перехідні характеристики САР при різних значеннях інтервалу прогнозування (1 - САР, 2-САРП_Л, 3 - САРП_К)

Приклад розрахунку запасів стійкості за коефіцієнтом передачі і часом запізнення в моделі ОУ для випадку коли інтервал прогнозування «квазіоптимальний» за критерієм (4) представлений на рисунку 5. Для системи оптимальної за критерієм (4) з коливальними перехідними процесами введення лінійного алгоритму прогнозування дає великі помилки, і фактично, модуль прогнозування стає підсилювачем сигналу, підвищуючи коефіцієнт передачі в замкнутому контурі, що підтверджується частотними характеристиками, представленими на рисунку 6.

Зі збільшенням часу прогнозування ситуація тільки погіршується і запас стійкості САР по кокоефіцієнт передачі ОК знижується. Доводиться знижувати інтервал прогнозу, що одночасно призводить до зниження динамічної точності САР. В цілому можна відзначити, що введення в контур зворотного зв'язку САР з високою частотою коливань власного руху ( $\approx 0.9$ рад / сек) лінійного модуля прогнозування не забезпечує одночасного підвищення динамічної точності САР і підвищення ii запасу стійкості (зокрема за коефіцієнтом передачі об'єкта) в порівнянні 3 використанням модуля прогнозування за кубічним сплайном. Слід також зазначити, що в системі з прогнозуванням по кубічному сплайну збільшення інтервалу прогнозу спочатку підвищує запас стійкості системи і за коефіцієнтом передачі і за часом запізнення, а при подальшому його збільшенні запас стійкості за коефіцієнтом передачі зменшується аж до нестійкості системи (рис.7). Цю особливість потрібно враховувати при введенні модуля прогнозування в систему без їі переналагодження. 

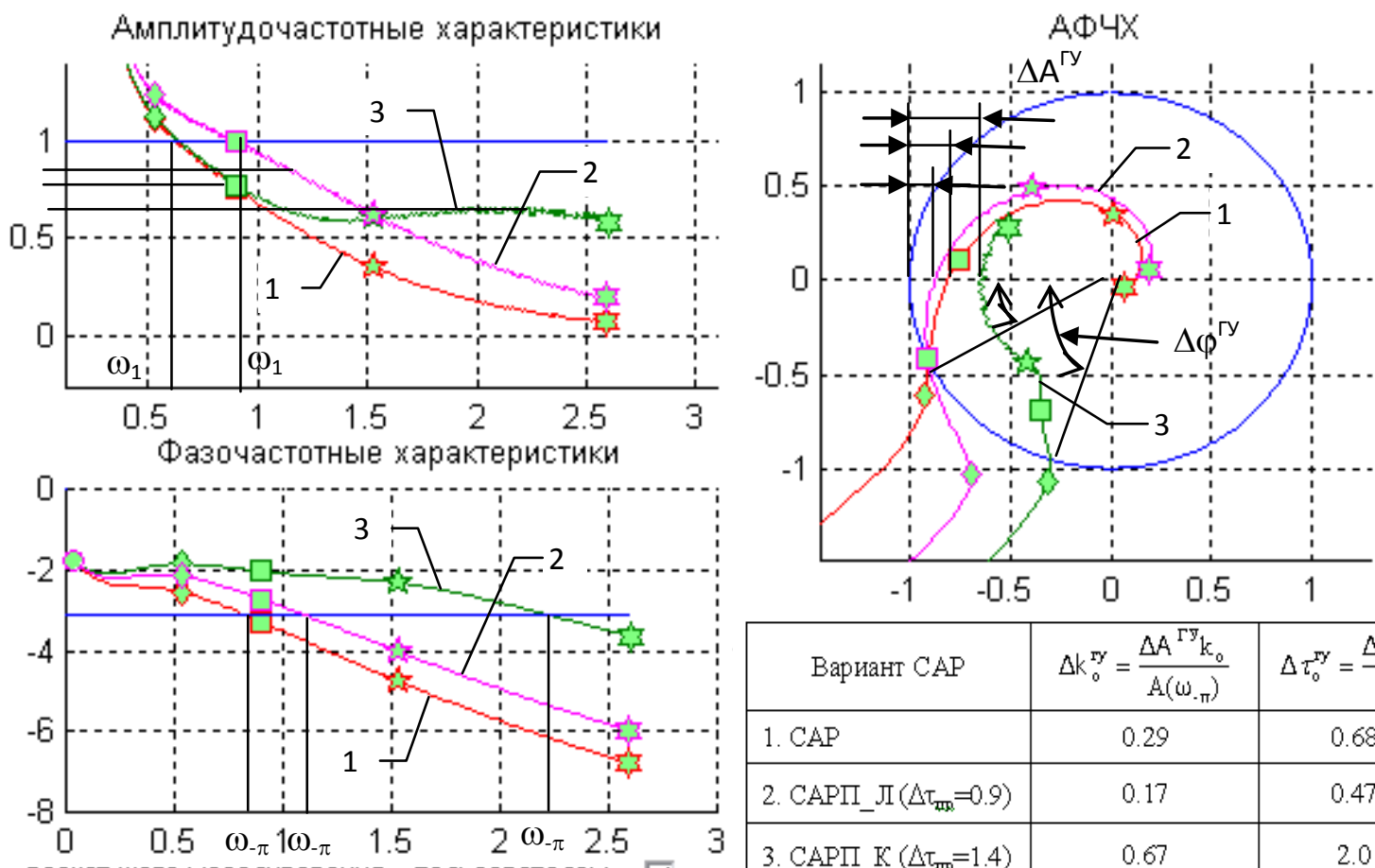

расчет шага моделирования - пользователем

-

$\checkmark$ еди

\begin{tabular}{|c|c|c|}
\hline Вариант CAP & $\Delta k_{0}^{\Gamma y}=\frac{\Delta A^{\Gamma y_{1}} k_{0}}{A\left(\omega_{\cdot \pi}\right)}$ & $\Delta \tau_{0}^{\mathrm{Yy}}=\frac{\Delta \varphi^{\Gamma \mathrm{y}}}{\omega_{1}}$ \\
\hline 1. $\mathrm{CAP}$ & 0.29 & 0.68 \\
\hline 2. CAPח_ $\Pi\left(\Delta \tau_{\text {m }}=0.9\right)$ & 0.17 & 0.47 \\
\hline 3. $\mathrm{CAP} \Pi \mathrm{K}\left(\Delta \tau_{\mathrm{mg}}=1.4\right)$ & 0.67 & 2.0 \\
\hline
\end{tabular}

Рис. 5 - Частотні характеристики розімкнутих САР з розрахунком значень їх запасів стійкості за коефіціснтом передачі $\Delta \mathrm{k}_{\circ}^{\mathrm{ry}} \mathrm{i}$ часом запізнення $\Delta \tau_{0}^{\mathrm{ry}}$ в моделі ОК

(1 - САР, 2-САРП_Л, 3 - САРП_К)
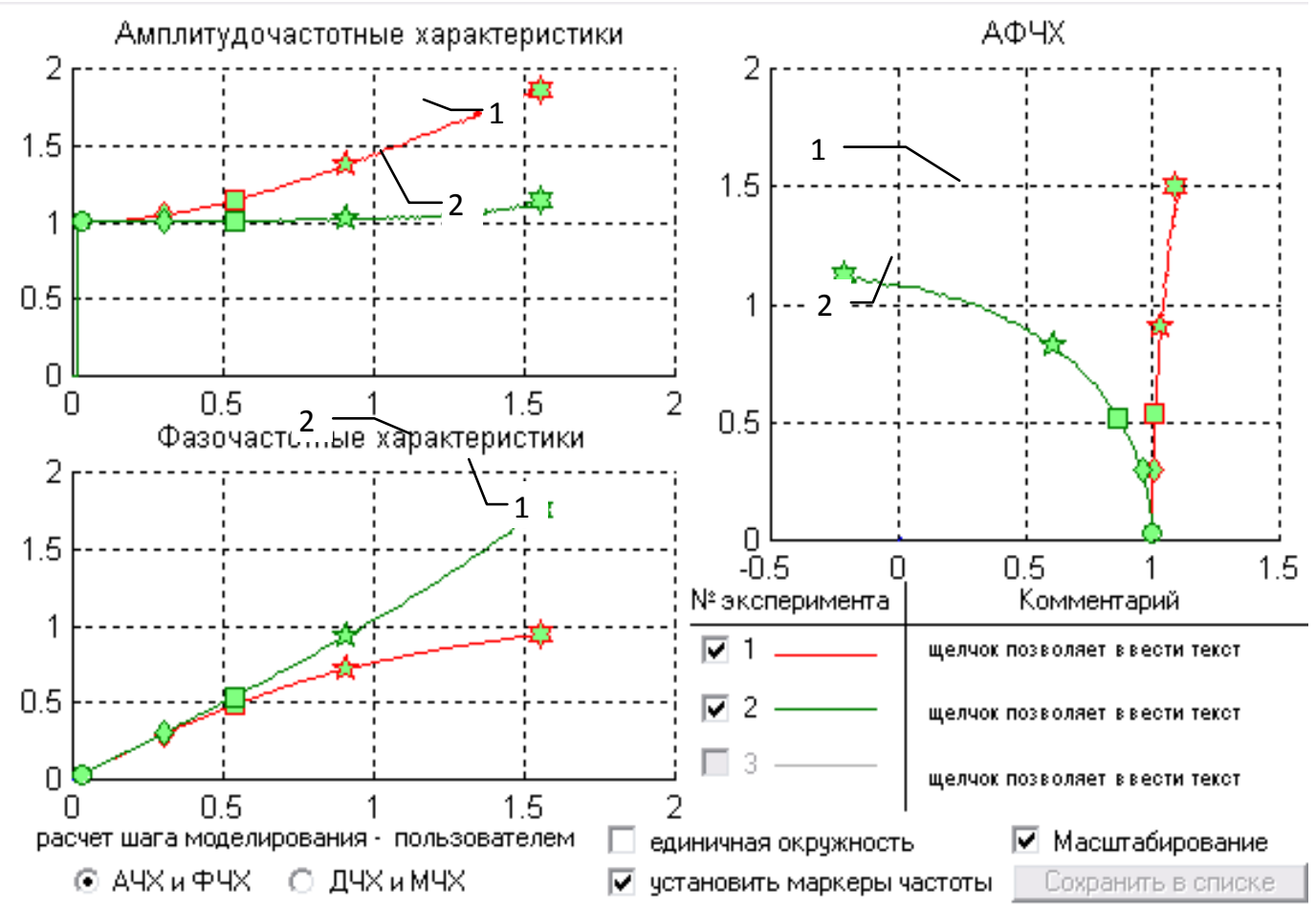

Рис. 6 - Частотні характеристики модулів прогнозування лінійного (1) і по кубічному сплайну (2) при однакових інтервалах прогнозування 1 с 


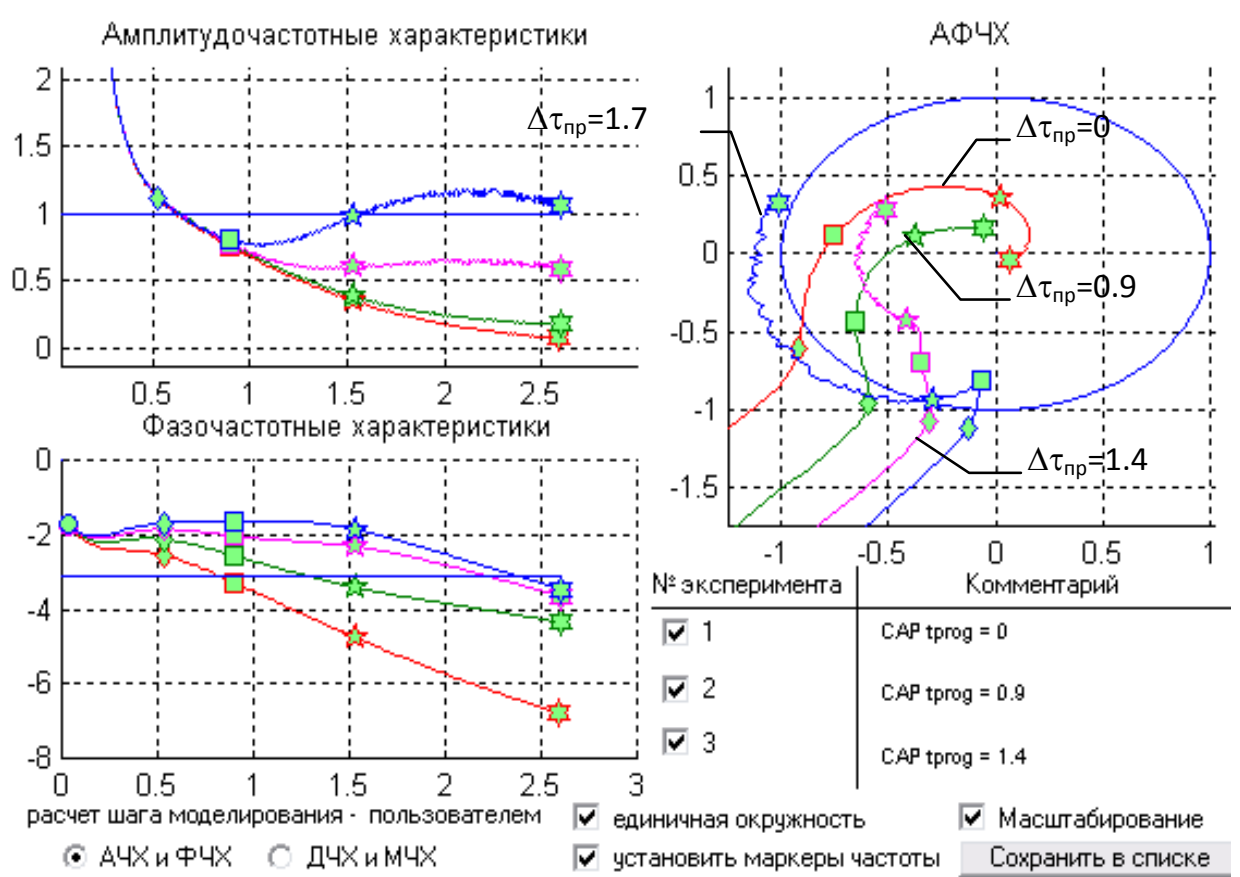

Рис. 7 - Частотні характеристики розімкнутої САР 3 прогнозуванням по кубічному сплайн, у які ілюструють залежність запасу стійкості САР по амплітуді і фазі

в залежності від заданого інтервалу прогнозу $\Delta \tau_{\text {пр }}$

Отримані результати є попередніми і не дозволяють зробити висновок про перевагу одного 3 варіантів систем. Для більш точної оцінки ефективності роботи розглянутих варіантів систем проведемо їх ОПС в однакових умовах і проаналізуємо їх роботу.

Об'єкти технологічного типу мають значний рівнем невизначеності і нестаціонарності їх параметрів. Тому оптимальний параметричний синтез САР будемо проводити в умовах параметричної невизначеності моделі ОК. В цьому випадку параметри моделі ОУ будуть задано не фіксованими значеннями, а діапазонами їх зміни ko $\in[0.96 \ldots 1.44], \mathrm{T} 1 \in[0.4 \ldots 0.6]$. ОПС в умовах параметричної невизначеності моделі ОК дозволить забезпечити стійкість САР для заданого діапазону зміни параметрів ОУ і приблизно однаковий запас стійкості САР за коефіцієнтом передачі і часу запізнювання. На рисунках 8-10 представлені результати ОПС САР без прогнозування і з прогнозуванням, а також результати перевірки цих систем на грубість, що підтверджують їх стійкість і працездатність в заданому діапазоні зміни параметрів ОК.

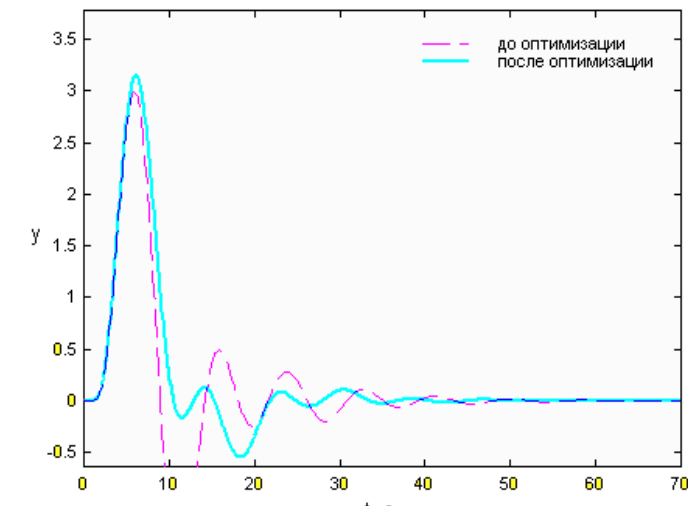

\begin{tabular}{|c|c|c|c|c|c|}
\hline \\
\hline $\begin{array}{c}\text { Имя } \\
\text { переменной }\end{array}$ & $\begin{array}{c}\text { Оптимальное } \\
\text { значение }\end{array}$ & $\begin{array}{l}\text { Нижний } \\
\text { предел }\end{array}$ & $\begin{array}{c}\text { Начальное } \\
\text { приближение }\end{array}$ & $\begin{array}{l}\text { Верхний } \\
\text { предел }\end{array}$ & $\begin{array}{l}\text { 3начение критерия } \\
\text { оптимальности: }\end{array}$ \\
\hline $\mathrm{kr} 1$ & 2.9323 & 0.2 & 3.54 & 10 & до - 221.1657 \\
\hline Tiz1 & 3.7391 & 0.2 & 2.76 & 20 & после - \\
\hline \multirow[t]{4}{*}{ Tpr1 } & 1.8656 & 0.3 & 1.6 & 5 & \multirow{2}{*}{$\begin{array}{l}\text { оптимизации. } \\
\text { Количество шагов } \\
\text { процедуры оптимизации: }\end{array}$} \\
\hline & & & & & \\
\hline & & & & & максимальное - 700 \\
\hline & & & & & фактическое - \\
\hline
\end{tabular}

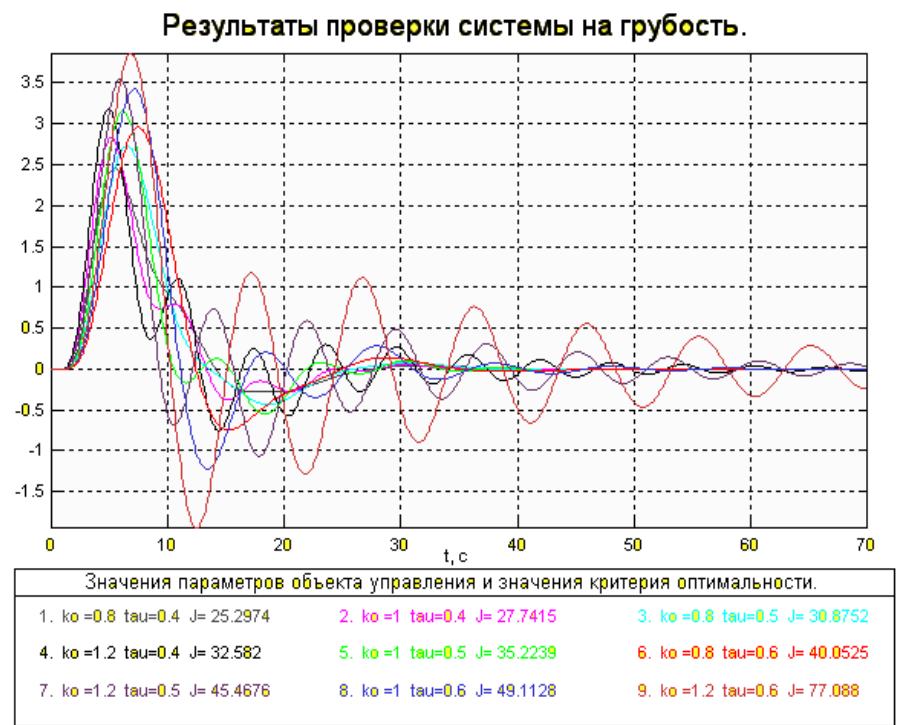

Рис. 8 - Результати оптимального параметричного синтезу і перевірки грубості САР з ПІД регулятором, яка реалізує принцип управління за відхиленням 

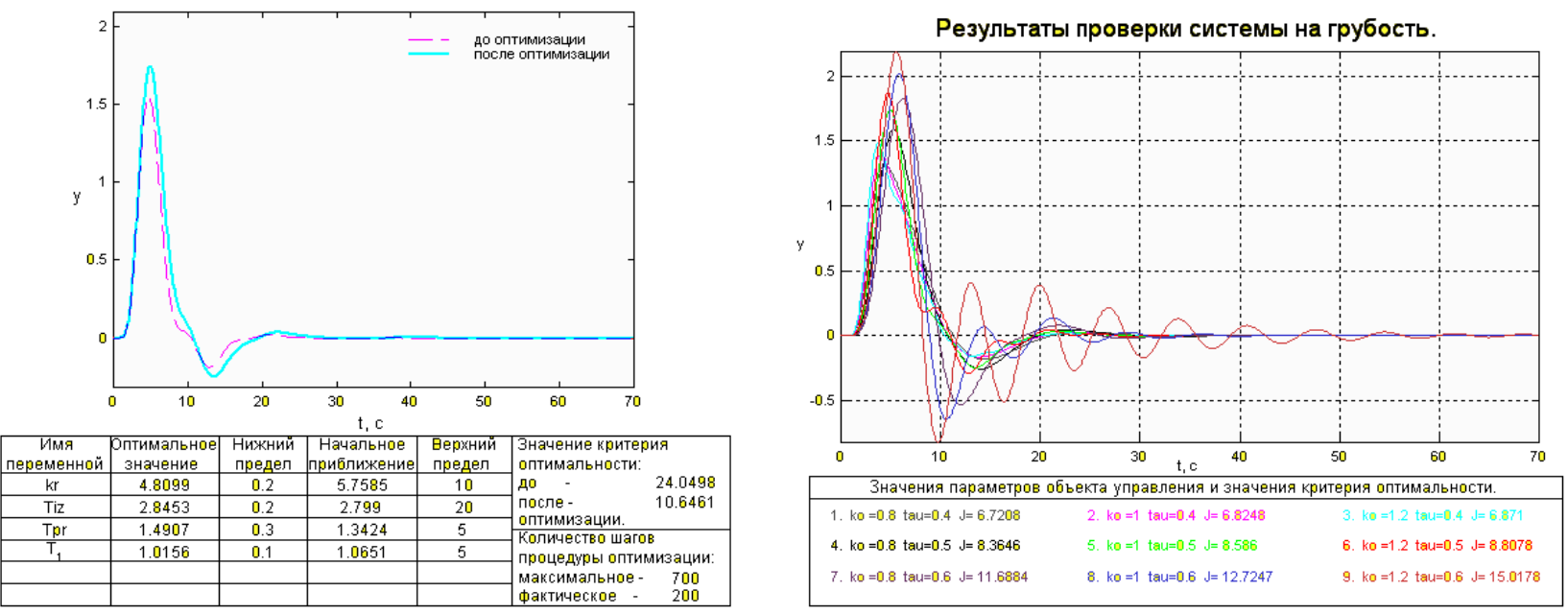

Рис. 9 - Результати оптимального параметричного синтезу і перевірки грубості САР з ПІД регулятором, яка реалізує принцип управління за прогнозом на основі кубічного сплайну
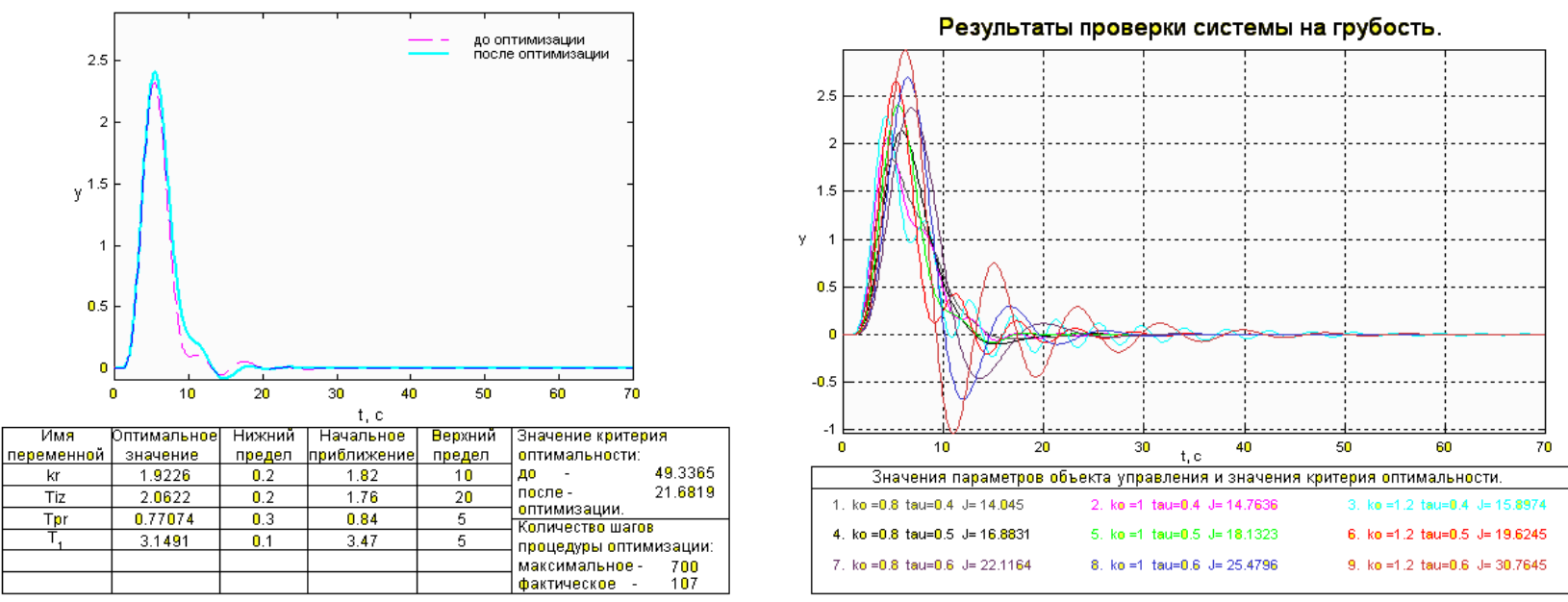

Рис. 10 - Результати оптимального параметричного синтезу і перевірки грубості САР з ПІД регулятором, яка реалізус принцип управління за прогнозом на основі лінійного прогнозування

На рисунку 11 наведено перехідні характеристики оптимальних САР для номінальних значень параметрів моделі ОК і значень параметрів, при яких інтегральний квадратичний критерій приймає мінімальне та максимальне значення. У всіх випадках САРП_К працює краще забезпечуючи зниження максимального динамічного відхилення біль ніж на 40\% та інтегрального показника якості у 3-4 рази в порівнянні з базовою САР, яка реалізує принцип керування за відхиленням.
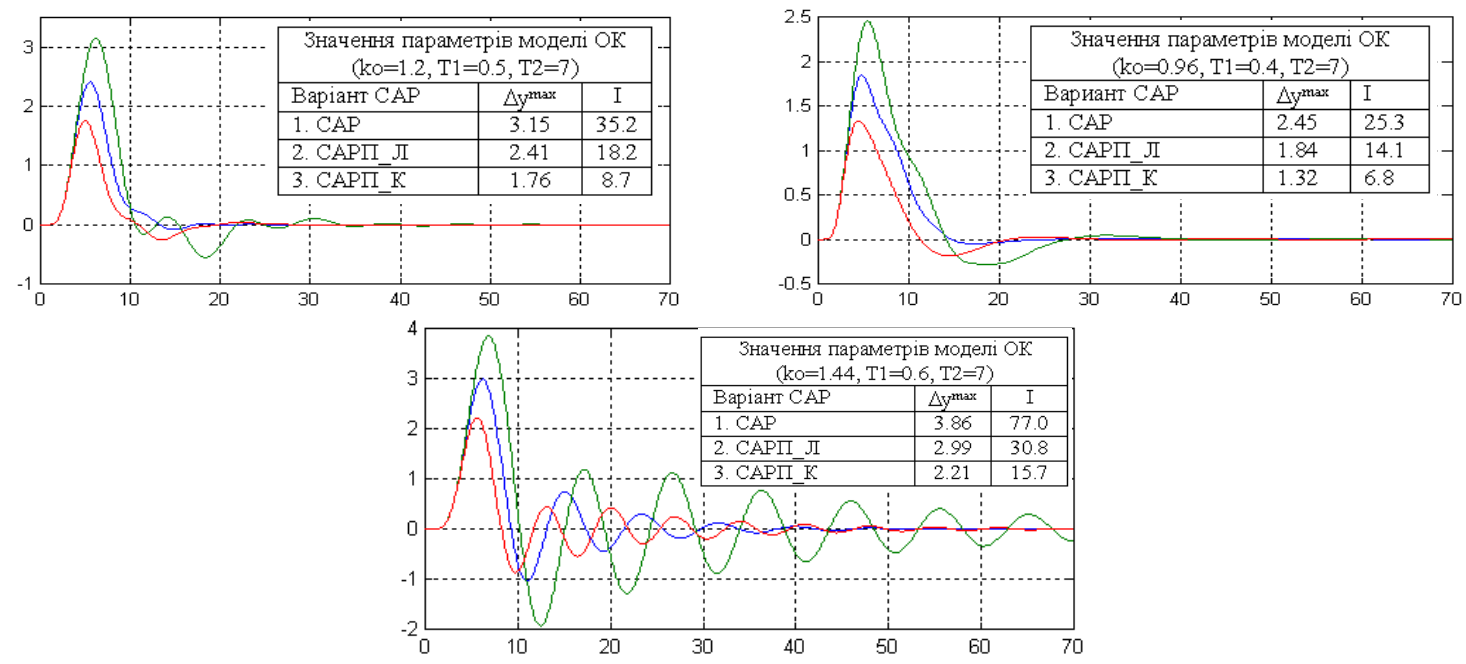

Рис. 11 - Перехідні характеристики САР при різних значення параметрів моделі ОК 


\title{
Висновки
}

1. Введення в замкнути контур регулювання модулю прогнозування за кубічним сплайном забезпечує підвищення динамічної точності САР та їі запасу стійкості за коефіцієнтом передачі та часом запізнення. Для тестової САР, яка оптимальна за інтегральним квадратичним показником якості, при збільшені інтервалу прогнозування в замкнутому контурі поступово збільшується динамічна точність та запас стійкості, при подальшому збільшенні інтервалу прогнозування відбувається збільшення еквівалентного коефіцієнта передачі модуля прогнозування, підвищення динамічної точності уповільнюється, а запас стійкості системи за коефіцієнтом передачі зменшується і система втрачає стійкість. Це потрібно враховувати при налаштуванні інтервалу прогнозування і реалізувати його само налагодження у системі. Також потрібно враховувати можливість зниження часу запізнення в каналі управління і розраховувати інтервал прогнозування виходячи 3 його мінімальних значень. Результати моделювання показали що введення модулю прогнозування в САР без пере налаштування параметрів регулятору дозволяє знизити максимальне динамічне відхилення на 30-35\%, інтегральний показник якості до 2 разів при значному підвищенні запасу стійкості.

2. Введення в контур регулювання САР, яка оптимальна за інтегральним квадратичним показником якості модулю прогнозування за лінійним законом значних покращень не забезпечило. Підвищення динамічної точності при збільшенні інтервалу прогнозування супроводжувалось швидким зниженням запасу стійкості САР. Частково це можна пояснити властивостями АЧХ (рис.6) модулю прогнозування який на частоті власного руху системи посилює сигнал значно більше ніж модуль прогнозування на основі кубічного сплайну. Тому налаштування інтервалу прогнозування потрібно проводити у сукупності з параметрами регулятору.

3. Результати оптимального параметричного синтезу проведеного в умовах параметричної невизначеності ОК підтвердили перевагу САР з прогнозуванням за кубічним сплайном перед САР з лінійним прогнозуванням та базовою САР. САР з прогнозуванням за кубічним сплайном забезпечує зниження максимального динамічного відхилення біль ніж на 40\% та інтегрального показника якості у 3-4 рази в порівнянні з базовою САР яка реалізує принцип керування за відхиленням.

\section{Список використаних джерел}

[1] Степанов М.Т., Хобин В.А. Прогнозирование вынужденного движения и его применение в системах гарантирующего управления //Автоматизація технологічних і бізнес-процесів. - Одеса, 2011. - № 5-6. - С. 20-25

[2] Пикина Г.А., Кузнецов М.С. Синтез линейных прогностических алгоритмов регулирования // Новое в российской электроэнергетике. - 2009. - № 10. - С. 40-44.

[3] Пикина Г.А., Кузнецов М.С. Прогностические типовые алгоритмы регулирования // Теплоэнергетика. - 2011. № 4. -C. 61-66.

[4] Степанов М.Т., Хобин В.А. Система автоматичного регулювання інваріантна до контрольованих збурень 3 прогнозуванням сигналу корекції по кубічному сплайну // Автоматизація технологічних і бізнес-процесів. - Одеса, 2020. - T. 12, № 1. - C. 67-74.

\section{References}

[1] M.T. Stepanov et al., "Prognozirovanie vyinuzhdennogo dvizheniya i ego primenenie v sistemah garantiruyuschego upravleniya," Automation of technological and business processes, no.5-6, pp.20-25, 2011.

[2] G.A. Pikina et al. "Sintez lineynyih prognosticheskih algoritmov regulirovaniya," Novoe v rossiyskoy elektroenergetike, vol. 10, pp. 40-44, 2009.

[3] G.A. Pikina et al. "Prognosticheskie tipovyie algoritmyi regulirovaniya," Teploenergetika, vol. 4, pp. 61-66, 2011.

[4] M.T. Stepanov et al. "Automatic control system invariant to controlled perturbations with forecasting of correction signal by cubic spline,” Automation of technological and business processes, vol 12, iss.1, pp. 64-70, 2020.

\section{УДК 621.577.4}

\section{МЕТОДИ ВИСОКОЕФЕКТИВНОГО ЛЮДИНО-МАШИННОГО ІНТЕРФЕЙСУ}

\author{
Волощук В. А. ${ }^{1}$, Некрашевич О. В. ${ }^{2}$, Ханко А. О. ${ }^{3}$ \\ 1,2,3 Національний технічний університет України «Київський політехнічний інститут імені Ігоря Сікорського», \\ м. Київ, Україна \\ ORCID: ${ }^{1}$ http://orcid.org/0000-0003-0687-8968, ${ }^{2}$ http://orcid.org/0000-0003-2263-3549, \\ ${ }^{3} \mathrm{http}: / /$ orcid.org/0000-0002-8682-9084 \\ E-mail: 1 vl.volodya@gmail.com, z ${ }^{2}$ olena.nekrashevych@gmail.com, ${ }^{3}$ bismarck195@gmail.com
}

Copyright (C) 2020 by author and the journal "Automation of technological and business - processes".

This work is licensed under the Creative Commons Attribution International License (CC BY).

http://creativecommons.org/licanses/by/4.0

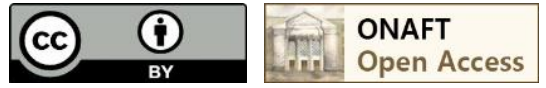

DOI: https://doi.org/10.15673/atbp.v12i4.1930 